\title{
AN EMPIRICAL INVESTIGATION OF THE EOE GOLD OPTIONS MARKET
}

\author{
Clifford A. BALL, Walter N. TOROUS and Adrian E. TSCHOEGL* \\ The University of Michigan, Ann Arbor, MI 48109, USA \\ Received May 1982, final version received July 1984
}

\begin{abstract}
On April 2, 1981, the European Option Exchange introduced the first organized exchange trading of options on spot gold. We study this new market for three months at its inception and in a parallel period a year later via various tests of rational boundary conditions. Additionally, we use call-put parity to infer implied risk free rates (IRFR's). Deviations of the IRFR's from the prevailing risk free rate permit the possibility of arbitrage through positions known as forward and reverse conversions. Our tests are modified to allow for transaction costs to more fully address the question of market efficiency.
\end{abstract}

\section{Introduction}

On April 2, 1981, the European Options Exchange (EOE) in Amsterdam introduced options on gold. Gold options have been sold by the Mocatta Metals Corporation of New York since 1973 and call options on gold futures have been actively traded on the Winnipeg Commodity Exchange since 1979. However, the EOE provided the first organized exchange for the trading in options whose payoff is directly contingent upon the price of gold.

Since the opening and the subsequent expansion of the Chicago Board Options Exchange (CBOE) there have been a number of investigations concerning option market efficiency [for example, Galai (1978), Chiras and Manaster (1978), Macbeth and Merville (1979), Rubinstein (1981), and Bhattacharya (1983)]. At the time of these studies, the CBOE, AMEX, Pacific, and Philadelphia exchanges dealt only in options on selected common stocks. The assets upon which options are written now includes commodities, precious metals, bonds, and futures contracts, and some studies examining these option markets are beginning to appear [Figlewski and Fitzgerald (1982), and Camerer (1982)].

The EOE gold options market provides an opportunity for the study of the behavior of a new options market and the characteristics of option pricing when the underlying asset is physical rather than financial. We

\footnotetext{
*We would like to thank the anonymous referees for their helpful suggestions, the European Options Exchange for providing the data, and William Keller, Lynn McMillan, and Hon-Meng Tang for their research assistance.
} 
investigate the effect of newness by examining the gold options market both at its inception and in a parallel period one year later. A signficant research advantage to this market is that the carrying costs on gold are negligible implying a negligible convenience yield, ${ }^{1}$ that is, gold receives no dividends. Furthermore, transaction costs on gold are minimal [Tschoegl (1980)]. The aims of this paper therefore are to exploit these advantages in investigating the efficiency of the gold options market at its inception and one year later.

Section 2 provides institutional information about the EOE and its gold options. Section 3 describes our data for both the 1981 and 1982 periods. We then test whether or not the observed prices satisfy rational option pricing boundary conditions in section 4 . Section 5 uses call-put parity to derive implied risk free rates and statistically examines their behavior while section 6 provides a summary and conclusions.

\section{The gold options market of the EOE}

The gold options market of the EOE is a central market for trading gold options. Trading follows the pattern devised for the stock options market of the EOE, established in April 1978, but under separate rules and regulations. One can trade both call and put options. That is, a gold option as listed on the EOE gives the holder the right (not the obligation) to purchase, in the case of a call, or to sell, in the case of a put, ten troy ounces of gold at a predetermined price, at any time up to the expiration date of the option. Gold options, therefore, are of the 'American' type. There are four possible expiration months in each year (February, May, August and November), of which normally three are open to trading. The expiry date is the Saturday following the third Friday of the expiration month. Gold options trade and are settled in US dollars per troy ounce. The EOE sets exercise prices at intervals of US\$25. Whenever the price of gold moves substantially, the EOE introduces a new exericse price.

All options trade by an open outcry auction system at the trading post of the Gold Options Market of the EOE between 10:30a.m. and 4:30 p.m. (local time). An order book official, responsible for overseeing the trading in gold options, supervises the trading post. His duties include holding limit orders placed in the book and displaying the highest bid and lowest offer, together with the number of contracts bid and offered. Table 1 summarizes the transactions costs (to the public) on gold options. These costs should be contrasted with those Phillips and Smith (1980, table 1) estimated for the CBOE of US\$10-\$65/option contract.

\footnotetext{
${ }^{1}$ We thank Jim Hoag and Mark Rubinstein for pointing this out to us. However, the convenience yield to other precious metals is not necessarily negligible. Hoag's empirical analyses [Hoag $(1971,1982)]$ suggests a substantial convenience yield to silver yet a negligible one for gold.
} 
Table 1

Transactions costs.

\begin{tabular}{|c|c|}
\hline Type and value of transaction & Commission \\
\hline \multicolumn{2}{|l|}{ Opening orders } \\
\hline Less than ten contracts & $\begin{array}{l}\$ 10 \text { per contract subject to a minimum } \\
\text { of } \$ 25 \text { per order }\end{array}$ \\
\hline Ten contracts (one round lot) & $\$ 80$ per order \\
\hline More than ten contracts & $\begin{array}{l}\$ 80 \text { plus } \$ 8 \text { per contract over } 10 \\
\text { contracts }\end{array}$ \\
\hline \multicolumn{2}{|l|}{ Closing orders } \\
\hline Less than ten contracts & $\begin{array}{l}\$ 3 \text { per contract subject to a minimum } \\
\text { of } \$ 10 \text { per order }\end{array}$ \\
\hline Ten contracts (one round lot) & $\$ 10$ per order \\
\hline More than ten contracts & $\begin{array}{l}\$ 20 \text { plus } \$ 2 \text { per contract over } 10 \\
\text { contracts }\end{array}$ \\
\hline \multicolumn{2}{|l|}{ Combination orders } \\
\hline Less than ten contracts & $\begin{array}{l}\$ 8 \text { per opening contract and } \$ 2 \text { per } \\
\text { closing contract subject to a minimum } \\
\text { of } \$ 25 \text { per order }\end{array}$ \\
\hline Ten or more contracts & $\begin{array}{l}\$ 8 \text { per opening contract and } \$ 2 \text { per } \\
\text { closing contract subject to a minimum } \\
\text { of } \$ 25 \text { per order }\end{array}$ \\
\hline
\end{tabular}

Recently the Montreal Stock Exchange announced that it has agreed with the EOE to establish a joint gold options market. Options bought on one exchange could be sold on the other. This will permit gold options trading over 12 consecutive hours.

\section{Data}

Our data consists of daily price and volume information for gold options at the EOE for the period April through June in 1981 and for the corresponding period in 1982. This includes the initial 56 trading days in 1981, and some 60 days in 1982.

As previously mentioned, the option contracts have 3 months between expiration dates so that on a given day the time to maturity on available options will be $\tau, \tau+0.25$ and $\tau+0.5$ years where $0 \leqq \tau \leqq 0.25$. The EOE originally selected exercise prices such that the options were close to the money. Initially (i.e., on April 2, 1981), the price of gold was $\$ 520.50$ and call exercise prices were set at $\$ 500, \$ 525$ and $\$ 550$. As the price of gold declined, the EOE introduced exercise prices of $\$ 475$ and $\$ 450$. On average, in both periods there were approximately 20 possible put and call contracts tradeable per day.

The data available provides closing prices corresponding to the last traded price of the day, and when no trade occurs the ask price is recorded. The only exceptions occur if either the last transaction occurs at a price below 
the bid price of the closing quotation when the bid price is employed or when the last transaction occurs at a price above the ask price of the closing quotation when the ask price is employed. In either case the last traded price is not indicative of the closing price.

The listed price of the underlying security is the daily p.m. fixing in the London gold market. Table 2 presents gold's p.m. fixing price behavior for the two periods. In the first period, the gold price rose at first, and then fell. In the second it rose, fell, and rose again to a level close to that at the beginning of the period.

Table 3 summarizes the option volume data for the two periods. Compared to the initial period, the second one saw a 73 percent increase in the total number of call contracts traded, and a 61 percent increase in contracts per day. For puts the growth was even more impressive, being 319 percent for total volume, and 296 percent for contracts per day. There was also a notable increase in total contract days (defined as the sum over all contracts of the number of days on which each contract traded).

Table 2

Gold p.m. fix price behavior.

\begin{tabular}{llrlr}
\hline & 1981 & & 1982 & \\
\hline First day & April 2 & $\$ 520.25$ & April 1 & $\$ 327.25$ \\
High & April 6 & $\$ 533.75$ & April 14 & $\$ 366.50$ \\
Low & June 25 & $\$ 446.50$ & June 21 & $\$ 296.50$ \\
Last day & June 25 & $\$ 446.50$ & June 30 & $\$ 318.00$ \\
Range & & $\$ 87.25$ & & $\$ 70.00$ \\
\hline
\end{tabular}

Table 3

Option trading volume.

\begin{tabular}{lclll}
\hline & $\begin{array}{l}\text { Total } \\
\text { volume }\end{array}$ & $\begin{array}{l}\text { Average } \\
\text { volume } \\
\text { per day }\end{array}$ & $\begin{array}{l}\text { Contract } \\
\text { days }^{\mathrm{a}}\end{array}$ & $\begin{array}{l}\text { Number } \\
\text { of contracts }\end{array}$ \\
\hline Calls & 8945 & 160 & 420 & 17 \\
Puts & 2895 & 52 & 219 & 17 \\
Calls & 15474 & 258 & 555 & 20 \\
Puts & 9242 & 154 & 404 & 20 \\
\hline
\end{tabular}

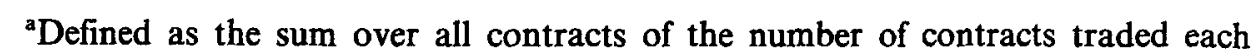
day.

${ }^{b}$ This is the sum of the number of contracts which were available for trading at some point during the period. During each three-month period a number of contracts expired and new ones were authorized. 


\section{Empirical tests of boundary condition for EOE gold options}

We first consider empirical tests based on the violation of rational boundary conditions derived from Merton's (1973) stochastic dominance arguments. These tests require no distributional assumptions on the underlying probability mechanism driving the gold price process. Although these tests are not particularly strong, if the market is inefficient with respect to simple information, it is improbable that it will be efficient with respect to some which is more complex or less freely available. For notational convenience we define

$C=$ call option price,

$P=$ put option price,

$K=$ exercise price,

$S=$ security price (gold),

$t=$ time to maturity,

$r=$ continuously compounded risk free rate.

Unfortunately, we only have closing price data and so mis-specification due to the resultant non-simultaneity is possible. Additionally, in some cases there is little contractual volume. These realistic imperfections serve to reduce the importance of observed violations of these tests. Moreover, observed arbitrage opportunities may be defused by transaction costs.

Merton (1973) establishes the following boundary conditions for American puts and calls assuming the absence of dividend payouts to the underlying security:

$$
\begin{aligned}
& C \geqq S-K e^{-r t}, \\
& P \geqq K-S .
\end{aligned}
$$

Since dividends are not paid to gold these boundary conditions must hold. Otherwise the EOE gold options market must be deemed inefficient in that arbitrage opportunities are available.

We examined boundary condition (1) for $r$ values from 0.02 to 0.20 . This allowed us to observe the sensitivity of the violation frequency to a plausible range for prevailing risk free rates. Table 4 presents the results. For calls only the number of violations at the lowest interest rates represent unambiguous violations of the boundary conditions. Three violations in 1981 and no violations in 1982. With regard to boundary condition (2), thirty-one violations were observed in 1981 and thirty-seven violations in 1982. However, a majority of these arbitrage opportunities dissipate once both transaction costs and the non-simultaneity of quoted gold and put prices are taken into account. These unambiguous violations occurred in options within five days of expiration. As is well known, option prices frequently behave erratically near expiration. Also, none of the above violations persisted to the next day. 
Table 4

Number of violations of the rational boundary condition.

\begin{tabular}{|c|c|c|c|c|c|c|c|c|c|c|c|}
\hline & \multicolumn{10}{|c|}{ Interest rate (\%) } & \multirow{2}{*}{$\begin{array}{l}\text { Number of } \\
\text { contract days }\end{array}$} \\
\hline & 2 & 4 & 6 & 8 & 10 & 12 & 14 & 16 & 18 & 20 & \\
\hline \multicolumn{12}{|c|}{1981} \\
\hline Calls & $3^{a}$ & 3 & 3 & 3 & 3 & 3 & 3 & 3 & 3 & 9 & 420 \\
\hline \multicolumn{12}{|c|}{1982} \\
\hline Calls & $0^{\mathrm{a}}$ & 0 & 0 & 0 & 0 & 3 & 6 & 14 & 23 & 40 & 555 \\
\hline
\end{tabular}

${ }^{a}$ Number of unambiguous violations.

Another empirical test of rational boundary conditions is based on option price convexity. Ceteris paribus, in the absence of dividend payouts the values of an American call option and an American put option are convex in their exercise price [Merton (1973)]. In other words, given exercise prices $K_{1}<K_{2}<K_{3}$ such that

$$
K_{2}=q K_{1}+(1-q) K_{3},
$$

then

$$
C\left(K_{2}\right) \leqq q C\left(K_{1}\right)+(1-q) C\left(K_{3}\right),
$$

and

$$
P\left(K_{2}\right) \leqq q P\left(K_{1}\right)+(1-q) P\left(K_{3}\right) .
$$

This is an important test since its violation permits the construction of a butterfly spread position to gain arbitrage profits. This position involves buying the two options with exercise prices $K_{1}$ and $K_{3}$ and writing the intermediate option.

For the butterfly spread test, we examined all possible combinations of those calls or puts with positive volume on each day. Table 5 presents the results.

For calls, the number of violations was lower in 1982, again absolutely and relatively. For puts, while the absolute number of violations increased, the relative frequency decreased. In all cases, the mean and even the maximum dollar amounts were within transactions costs to the public. Since we do not know their transactions costs, it is not clear whether or not floor brokers and market makers could profit from the opportunities.

In the majority of cases, the call violations involved an option that was deep out of the money. These options often are mis-priced by the Black- 
Table 5

Number and magnitude of convexity test violations.

\begin{tabular}{lccccc}
\hline & $\begin{array}{l}\text { Number of } \\
\text { violations }\end{array}$ & Mean & $\begin{array}{l}\text { Standard } \\
\text { deviation }\end{array}$ & Maximum & $\begin{array}{l}\text { Number of } \\
\text { tests }\end{array}$ \\
\hline Calls & 26 & $\$ 1.46$ & $\begin{array}{c}1981 \\
\$ 1.63\end{array}$ & $\$ 8.50$ & 173 \\
Puts & 1 & $\$ 2.00$ & n.a. & $\$ 2.00$ & 30 \\
& & & 1982 & & \\
Call & 24 & $\$ 1.91$ & $\$ 2.22$ & $\$ 7.50$ & 421 \\
Puts & 8 & $\$ 1.24$ & $\$ 0.79$ & $\$ 2.50$ & 404 \\
\hline
\end{tabular}

Scholes (1973) formula, though this phenomenon does not invalidate the apparent violation. In addition, there were three occasions in 1981 when a violation existed for two consecutive days. There was one such case for puts and one for calls in 1982.

\section{Call-put parity and the risk free rate}

Stoll (1969) established a relationship between the price of call and put options written on the same underlying asset and with the same expiry date. Under quite general distributional assumptions on asset price behavior and in the absence of dividends,

$$
C-P=S-K \mathrm{e}^{-r t} .
$$

This call-put parity only holds when it is not rational to prematurely exercise the options. In the absence of dividends it is never rational to prematurely exercise an American call option [Merton (1973)]. However, this is not the case for American put options. Suppose the price of the underlying security fell so low that the strategy of immediate exercise of the American put option and investment of the proceeds at the prevailing risk free rate earned a payoff at the option's expiration of more than the exercise price. Because, at expiration, the American put can be worth at most its exercise price, the immediate exercise strategy dominates the holding strategy and hence under these circumstances premature exercise would be rational. Indeed, there exists a critical stock price for each time point at which premature exercise becomes optimal. This critical stock price as a function of time plays a fundamental role in the numerical procedures devised for the valuation of American put options [Brennan and Schwartz (1977)].

We can use eq. (4) and market call and put prices to infer a market implied risk free rate (IRFR). This is of practical as well as theoretical interest. Practitioners use eq. (4) to generate positions known as 'forward' 
and 'reverse conversions' [Klemkosky and Resnick $(1979,1980)$ and Anders (1982)]. ${ }^{2}$ Deviations of the IRFR from the prevailing market risk free rate indicate the possibility of arbitrage profits.

Due to the possibility of premature exercise it is reasonable to expect that for deep in the money American put options eq. (4) will be significantly distorted. However, for American put options which are not in the money the probability of premature exercise is quite small and hence we may use eq. (4) to obtain approximately unbiased IRFRs. Assuming eq. (4) holds, tables $6 \mathrm{a}$ and $6 \mathrm{~b}$ provide summary statistics on the resultant IRFRs. The mean IRFR tends to be much lower for the higher exercise price contracts than for the lower ones demonstrating a systematic downward bias induced by the deep in the money American put options. In addition, the mean IRFRs are lower for 1982 than for 1981 consistent with the general decrease in interest rates over that period. In line with common practice we will use the U.S. Treasury bill ( $\mathrm{T}$-bill) rate as a proxy for the prevailing risk free rate [Klemkosky and Resnick $(1979,1980)]$. We now indicate strategies for achieving arbitrage profits under our assumptions.

If the IRFR exceeds the T-bill rate then the EOE gold options trader will engage in a forward conversion guaranteeing a risk free lending rate greater than the T-bill rate. This implied risk free lending rate is a priori certain since the forward conversion involves buying gold, writing an American call on gold (which will never be prematurely exercised), and buying an American put on gold, which will only be prematurely exercised to the trader's advantage.

If the T-bill rate exceeds the IRFR, arbitrage profits may be illusory. By engaging in a reverse conversion the EOE gold options trader generates an initial borrowing rate less than the T-bill rate. However, this borrowing rate is not a priori certain. Recall, a reverse conversion involves shorting gold, buying an American call on gold and writing an American put on gold. The American put may be exercised prematurely to the trader's disadvantage thereby increasing the realized borrowing rate of return. As the American put option becomes deeper in the money the possibility of premature exercise increases, rendering the IRFR an inappropriate measure of the realizable borrowing rate.

As Anders (1982) reports, traders on the U.S. option exchanges engage in both forward and reverse conversions using, as is consistent with our results, at the money options on non-dividend paying stocks. He reports that the former are rare (as one would expect as they are true arbitrage opportunities), but that the latter are apparently not uncommon.

\footnotetext{
${ }^{2}$ Forward conversions involves buying the underlying stock and a put, and selling a call with the same exercise price and maturity as the put. Reverse conversion involves shorting the stock, selling a put, and buying a call, again matching exercise prices and maturities for all three contracts.
} 
Table 6a

Implied risk free rate (IRFR) - summary statistics 1981.

\begin{tabular}{lcll}
\hline Contract & $\begin{array}{l}\text { Sample } \\
\text { size }\end{array}$ & Mean & $\begin{array}{l}\text { Standard } \\
\text { error }\end{array}$ \\
\hline May 475 & 5 & 0.156 & 0.897 \\
May 500 & 24 & 0.218 & 0.297 \\
May 525 & 13 & 0.145 & 0.082 \\
May 550 & 4 & 0.077 & 0.072 \\
Aug 450 & 5 & 0.035 & 0.196 \\
Aug 475 & 20 & 0.121 & 0.102 \\
Aug 500 & 32 & 0.142 & 0.031 \\
Aug 525 & 18 & 0.114 & 0.024 \\
Aug 550 & 2 & 0.093 & 0.017 \\
Nov 450 & 1 & 0.149 & n.a. \\
Nov 475 & 5 & 0.132 & 0.021 \\
Nov 500 & 9 & 0.123 & 0.023 \\
Nov 525 & 1 & 0.091 & n.a. \\
Nov 550 & 2 & 0.072 & 0.029 \\
Feb 450 & 1 & 0.145 & n.a. \\
Feb 475 & 1 & 0.108 & n.a. \\
Feb 500 & 1 & 0.115 & n.a. \\
\hline
\end{tabular}

Table $6 \mathrm{~b}$

Implied risk free rate (IRFR) - summary statistics 1982.

\begin{tabular}{lccl}
\hline Contract & $\begin{array}{l}\text { Sample } \\
\text { size }\end{array}$ & Mean & $\begin{array}{l}\text { Standard } \\
\text { error }\end{array}$ \\
\hline May 300 & 1 & -0.019 & n.a. \\
May 325 & 17 & 0.602 & 2.024 \\
May 350 & 23 & 0.287 & 1.144 \\
May 375 & 11 & 0.120 & 0.672 \\
May 400 & 1 & 0.168 & n.a. \\
May 425 & 1 & 0.100 & n.a. \\
Aug 300 & 15 & 0.013 & 0.279 \\
Aug 325 & 37 & 0.104 & 0.035 \\
Aug 350 & 50 & 0.099 & 0.039 \\
Aug 375 & 21 & 0.085 & 0.020 \\
Aug 400 & 7 & 0.097 & 0.025 \\
Aug 425 & 3 & 0.052 & 0.011 \\
Nov 300 & 11 & 0.095 & 0.028 \\
Nov 325 & 24 & 0.085 & 0.039 \\
Nov 350 & 26 & 0.093 & 0.026 \\
Nov 375 & 8 & 0.089 & 0.017 \\
Nov 400 & 4 & 0.088 & 0.027 \\
Feb 300 & 5 & 0.076 & 0.004 \\
Feb 325 & 2 & 0.132 & 0.003 \\
Feb 350 & 1 & 0.094 & n.a. \\
\hline
\end{tabular}


If such arbitrage opportunities occur on the long-established American exchanges it is not improbable that they exist on the EOE. The volatilities of the IRFRs as evidenced in tables $6 \mathrm{a}$ and $6 \mathrm{~b}$ imply that they could exist. Restricting our attention to forward conversions, and assuming the corresponding U.S. Treasury bid yield appropriately measures the cost of borrowing, we identified 47 (out of 148) occasions in 1981 and 59 (out of 268) occasions in 1982 in which this implied risk free lending rate exceeded the U.S. Treasury bill bid yield.

However, our preceding analysis has not taken into account the various transaction costs incurred in establishing forward conversions. Prohibitive transaction costs may transform apparent profits into losses. In order to appropriately adjust the implied risk free lending rate, we now investigage the transaction costs associated with forward conversions.

We let $T_{\mathrm{c}}, T_{\mathrm{p}}$, and $T_{\mathrm{s}}$ denote the transaction costs incurred in writing a call, buying a put, and buying the underlying security, respectively. Table 1 details the transaction costs on EOE gold options. The commission charged on a purchase of gold at the London fixing is $0.25 \%$. On the forward conversion's expiration date the underlying security is delivered and in return the exercise price $K$ is received. Sales of gold via the London fixing are commission-free. In the presence of these transaction costs, the call-put parity relationship becomes

$$
\left(C-T_{\mathrm{c}}\right)-\left(P+T_{\mathrm{p}}\right)-\left(S+T_{\mathrm{s}}\right)=-\mathrm{Ke}^{-\boldsymbol{r t}} .
$$

In implying this risk free lending rate we take $T_{c}=\$ 8 /$ contract, $T_{p}=\$ 8 /$ contract and $T_{\mathrm{s}}=0.25 \%$.

Tables $7 \mathrm{a}$ and $7 \mathrm{~b}$ provide a summary statistics on the resultant adjusted IRFRs. As would be expected, the implied risk free lending rates are reduced by these transaction costs. Furthermore, the degree of reduction is more pronounced for the short term to maturity options. To determine whether arbitrage opportunities remain, an appropriate risk free borrowing rate must be employed.

If we continue to use the T-bill rate, arguing that this is the opportunity cost to a trader borrowing from himself to invest in the riskless forward conversion, transaction costs reduce the number of arbitrage opportunities to 12 in 1981 and 13 in 1982. However, marginal investors cannot borrow at the T-bill rate. At best these investors may borrow from their broker over the very short term at a premium over and above the prevailing call loan rate. Following Rubinstein and Cox (1978), we approximate this very shortterm borrowing rate by $3 / 4 \%$ above the call loan rate. To approximate longer-term borrowing rates, the difference between the call loan rate plus $3 / 4 \%$ and the shortest term T-bill rate is added to the rate of interest on a $T$ bill maturing closest to the option's expiration date. 
Table 7a

Adjusted implied risk free rate - summary statistics 1981 .

\begin{tabular}{lccl}
\hline Contract & $\begin{array}{l}\text { Sample } \\
\text { size }\end{array}$ & Mean & $\begin{array}{l}\text { Standard } \\
\text { error }\end{array}$ \\
\hline May 475 & 5 & -0.911 & 2.041 \\
May 500 & 24 & -0.077 & 0.231 \\
May 525 & 13 & -0.016 & 0.136 \\
May 550 & 4 & -0.055 & 0.085 \\
Aug 450 & 5 & -0.014 & 0.198 \\
Aug 475 & 20 & 0.079 & 0.103 \\
Aug 500 & 32 & 0.109 & 0.030 \\
Aug 525 & 18 & 0.085 & 0.027 \\
Aug 550 & 2 & 0.065 & 0.018 \\
Nov 450 & 1 & 0.127 & n.a. \\
Nov 475 & 5 & 0.112 & 0.021 \\
Nov 500 & 9 & 0.105 & 0.023 \\
Nov 525 & 1 & 0.077 & n.a. \\
Nov 550 & 2 & 0.057 & 0.031 \\
Feb 450 & 1 & 0.131 & n.a. \\
Feb 475 & 1 & 0.095 & n.a. \\
Feb 500 & 1 & 0.102 & n.a. \\
\hline
\end{tabular}

Table $7 b$

Adjusted implied risk free rate - summary statistics 1982.

\begin{tabular}{lcrl}
\hline Contract & $\begin{array}{l}\text { Sample } \\
\text { size }\end{array}$ & Mean & $\begin{array}{l}\text { Standard } \\
\text { error }\end{array}$ \\
\hline May 300 & 1 & -0.152 & n.a. \\
May 325 & 17 & 0.043 & 1.161 \\
May 350 & 23 & -0.113 & 0.485 \\
May 375 & 11 & 0.000 & 0.841 \\
May 400 & 1 & 0.040 & n.a. \\
May 425 & 1 & -0.087 & n.a. \\
Aug 300 & 15 & -0.040 & 0.282 \\
Aug 325 & 37 & 0.057 & 0.040 \\
Aug 350 & 50 & 0.059 & 0.042 \\
Aug 375 & 21 & 0.051 & 0.024 \\
Aug 400 & 7 & 0.070 & 0.023 \\
Aug 425 & 3 & 0.025 & 0.013 \\
Nov 300 & 11 & 0.069 & 0.029 \\
Nov 325 & 24 & 0.066 & 0.039 \\
Nov 350 & 26 & 0.072 & 0.028 \\
Nov 375 & 8 & 0.071 & 0.013 \\
Nov 400 & 4 & 0.072 & 0.023 \\
Feb 300 & 5 & 0.058 & 0.004 \\
Feb 325 & 2 & 0.116 & 0.003 \\
Feb 350 & 1 & 0.078 & n.a. \\
\hline
\end{tabular}


A comparison of these borrowing rates and the adjusted IRFRs indicate three arbitrage opportunities via forward conversions were to be found in the EOE gold options market in 1981, and two in 1982. All involved options close to maturity. In 1981, the three cases occurred in May options with three and two days to maturity, with two cases representing an opportunity which persisted over two days. In 1982, both cases occurred on the day before expiration.

\section{Summary and conclusion}

The EOE introduced options on gold in April 1981. These options have a particular attraction for empirical research since the underlying security pays no dividends. In this paper we have taken advantage of this feature in applying various tests of market efficiency. While we observed occasions of apparent mis-pricing these could be due to data problems, particularly nonsimultaneity of quoted prices.

We first employed tests based on Merton's (1973) rational boundary conditions. These indicated minimal deviations from market efficiency. Further, all of our tests indicated that these violations declined absolutely or relatively as the market became less new or thin. Next, we used call-put parity to infer an IRFR which provided an additional test of market efficiency. When the IRFR deviates from the prevailing risk free rate, traders may engage in arbitrage through establishing positions known as forward and reverse conversions. Our results indicate that, apart from the quality of our data, such opportunities may indeed have existed. However, once transaction costs were considered these arbitrage opportunities were almost entirely eliminated.

In summary, our analysis concludes that the EOE gold options market is efficient. At its inception, some possible pricing inefficiencies may have existed, but this finding is subject to caveats concerning the data. However, with the passage of time the number and magnitude of such inefficiencies has decreased.

\section{References}

Anders, George, 1982, Brokers' reverse conversion strategies are seen fueling surge in short interest, Wall Street Journal, March 22, p. 14.

Bhattacharya, Mihir, 1983, Transactions data tests of efficiency of the Chicago board options exchange, Journal of Financial Economics 12, no. 2, 161-185.

Black, Fisher and Myron Scholes, 1973, The pricing of options and corporate liabilities, Journal of Political Economy 81, 637-654.

Brennan, Michael J. and Eduardo Schwartz, 1977, The valuation of American put options, Journal of Finance 32, 449-462.

Camerer, Colin, 1982, The pricing and social value of commodity options, Financial Analysts Journal 38 , no. $1,62-66$.

Chiras, Donald and Steven Manaster, 1978, The information content of option prices and a test of market efficiency, Journal of Financial Economics 6, nos. 2/3, 213-234. 
Figlewski, Stephen and M. Desmond Fitzgerald, 1982, The price behavior of London commodity options, Review of Research in Futures Markets 1, no. 1, 91-104.

Galai, Dan, 1978, Empirical tests of boundary conditions for CBOE options, Journal of Financial Economics 6, nos. 2/3, 187-211.

Hoag, James W., 1971, A comparison of interest rates of various money market instruments and term structure implied in silver futures prices, Unpublished manuscript (Stanford University, Stanford, CA).

Hoag, James W., 1982, The valuation of commodity options, Unpublished manuscript (University of California, Berkeley, CA).

Klemkosky, R. and B. Resnick, 1979, Put-call parity and market efficiency, Journal of Finance 34, 1141-1155.

Klemkosky, R. and B. Resnick, 1980, An ex ante analysis of put-call parity, Journal of Financial Economics 8, 363-378.

McBeth, James D. and Larry J. Merville, 1979, An empirical examination of the Black-Scholes call option pricing model, Journal of Finance 34, 1173-1186.

Merton, Robert, 1973, Theory of rational optiong pricing, The Bell Journal of Economics 4, 141-183.

Phillips, S. and C. Smith, Jr., 1980, Trading costs for listed options: The implications for market efficiency, Journal of Financial Economics 8, 179-201.

Rubinstein, Mark, 1981, Nonparametric tests of alternative option pricing models using all reported trades and quotes on the 30 most active CBOE option classes from August 23, 1976 through August 31, 1978, Unpublished manuscript (University of California, Berkeley, CA).

Rubinstein, Mark and John Cox, 1978, Options markets (Prentice-Hall, Englewood Cliffs, NJ) forthcoming.

Stoll, Hans, 1969, The relationship between put and call option prices, Journal of Finance 24, 801-824.

Tschoegl, Adrian E., 1980, Efficiency in the gold market - A note, Journal of Banking and Finance 4, no. 4, 371-379. 